Disponível em:

http://editora.unoesc.edu.br/index.php/race

RACE, Joaçaba, v. 17, n. 2, p. 507-534, maio/ago. 2018

\title{
QUALIDADE DO SERVIÇO NO COMÉRCIO VAREJISTA DE VESTUÁRIO: LACUNAS PERCEBIDAS PELA CLIENTELA FEMININA
}

Quality of service in retail clothing: gaps perceived by female customers

Domingos Fernandes Campos

E-mail: domingos_campos@uol.com.br

Doutor em Engenharia de Produção pela Universidad Politécnica de Madrid, Espanha; Mestre em Engenharia de Produção pela Universidade Federal de Santa Catarina; Professor no Programa de Pós-graduação em Administração da Universidade Potiguar.

Endereço para contato: Rua Floriano Peixoto, Petrópolis, 59000-000, Natal, Rio Grande do Norte, Brasil.

Ellen Figueiredo Leão Garcia E-mail: figueiredo.ellen@gmail.com

Mestre em Administração pela Universidade Potiguar; Especialista em Gestão de Pessoas e Marketing pela Pontifícia Universidade Católica de Goiás; Professora no Instituto Federal de Educação, Ciência e Tecnologia da Paraíba.

Daniel Cavalcanti Fernandes Campos

E-mail: danielcidadedosom@gmail.com

Mestre em Administração Pública pela Universidade Federal do Rio Grande do Norte;

Especialista em Gestão Estratégica em Marketing pela Universidade Federal do Rio Grande do Norte; Produtor Cultural na Universidade Federal do Rio Grande do Norte.

Evadio Pereira Filho

E-mail: evadio.filho@gmail.com

Mestre em Administração pela Universidade Potiguar; Doutorando em Administração pela Universidade Federal do Rio Grande do Norte; Professor no Instituto Federal de Educação, Ciência e Tecnologia da Paraíba.

Artigo recebido em 20 de setembro de 2017. Aceito em 12 de junho de 2018. 


\section{Resumo}

No presente estudo apresenta-se um comparativo de expectativas e percepções do serviço no segmento do vestuário em três centros comerciais - um comércio popular de bairro, um shopping center e uma rua de comércio tradicional de alto poder aquisitivo - na Cidade de Natal, RN. Foram coletadas expectativas e percepções do serviço recebido de 1.155 mulheres sobre um conjunto de 23 atributos. O modelo das lacunas de qualidade foi utilizado para a avaliação da qualidade do serviço percebido em cada área. Em todos os centros comerciais houve predominância de lacunas negativas, indicando que as clientes percebem o serviço oferecido aquém de suas necessidades. O confronto entre os níveis de importância e as lacunas de qualidade possibilitou apontar os atributos que deveriam receber uma atenção destacada dos gestores. Os resultados sugerem que o comércio no bairro popular tende a atrair clientes menos exigentes. Ao mesmo tempo, esses clientes percebem níveis mais baixos de qualidade no serviço recebido.

Palavras-chave: Qualidade do serviço. Lacunas de qualidade. Varejo. Matriz de importância e desempenho.

Abstract

The purpose of this paper is to compare expectations and perceptions of service in the clothing segment in three commercial centers - a district, a shopping center and a strip retail - in Natal, $R N$. Expectations and perceptions of received service were collected from 1,155 women in a set of 23 attributes. The model of quality gaps was used to assess the quality of service perceived in each area. In all retail centers there was predominance of negative gaps, indicating that customers perceive the service offered below their needs. The confrontation between the levels of importance and quality gaps allowed to identify the attributes that should be given a prominent attention from managers. The results suggest that commerce in the popular neighborhood tends to attract less demanding customers. At the same time, these customers perceive lower quality levels in the service received.

Keywords: Quality service. Quality gaps. Retail. Importance-performance analysis.

\section{INTRODUÇÃO}

Nos últimos 50 anos, o comércio varejista nas cidades tem passado por grandes transformações, as quais foram desencadeadas por múltiplos fatores de ordens econômica, espacial e organizacional. Por um lado, grandes grupos econômicos nacionais e internacionais passaram a intervir de forma direta nas relações de domínio e poder mediante a formação de grandes cadeias de lojas e supermercados; por outro, as transformações sociais alteraram o modus vivendi da população que hoje busca a se- 
gurança, o lazer e as compras em um mesmo espaço comercial, economizando tempo e dinheiro. Nos centros urbanos, vem se tornando peculiar a implantação de núcleos comerciais diferenciados pelo poder aquisitivo do seu entorno, além de grandes templos de consumo como os shopping centers.

A crescente mobilidade urbana promoveu a descentralização do comércio citadino, favorecendo o surgimento de novos núcleos em outras áreas da cidade. Se de um lado o surgimento dos grandes grupos comerciais fez declinar a participação dos pequenos e médios negócios, de outro, o amplo crescimento das franquias nacionais e internacionais agregou novas possibilidades. As cidades de médio e grande porte, via de regra, contemplam possibilidades que vão desde o comércio tradicional central, perpassando pelo comércio de bairros diferenciados pelo contexto social local, até os centros comerciais limitados ou de grande porte, como os shopping centers.

A escolha de um ou outro depende, basicamente, de uma multiplicidade de fatores que envolvem várias dimensões como acesso, segurança, infraestrutura, atendimento, variedade dos produtos, imagem e preços. Essas dimensões extrapolam o conjunto de variáveis com as quais um único estabelecimento comercial jogaria na retenção ou ampliação de sua clientela. Cada núcleo ou centro comercial oferece um conjunto de fatores de atratividade que pode acolher um maior ou menor número de clientes. Assim, pressupõe-se que a escolha e o nível de frequência dos clientes estão associados ao serviço oferecido como um todo pelos núcleos e centros comerciais da cidade.

Parente, Miotto e Barki (2007) afirmam que muitas redes varejistas preferem abrir suas lojas em shoppings, pois estes atendem às classes mais altas. Não obstante, os núcleos comerciais de rua ou de bairro ainda detêm a maior parte das vendas varejistas do País. Os núcleos comerciais possuem alguns atributos urbanísticos que ressaltam a sua relevância na humanização das cidades, uma vez que a construção de shopping centers afastados contribui no sentido de tornar a cidade menos integrada do ponto de vista urbanístico, social e humano.

A pesquisa de Linovski (2012) revela que os comércios de rua oferecem um espaço de varejo acessível para pequenas empresas não disponíveis em outros centros comerciais e os espaços são vistos como altamente desejáveis para muitos tipos de negócios alternativos. Existiria, ademais, um claro benefício em ter alguns espaços nas cidades com menos controles e barreiras ao acesso. Uma forma de projeto urbano que acomoda e incentiva uma diversidade de usos e usuários é um valor ideal para se alcançar.

No presente trabalho avaliam-se as expectativas de clientes do sexo feminino e o serviço prestado por três importantes centros comerciais da Cidade de Natal na comercialização de bens de vestuário. Os centros são representados, respectivamente, 
por um comércio de bairro popular, por um comércio de rua (strip retail), diferenciado, localizado em um bairro de alto poder aquisitivo, e pelo maior shopping center da Cidade. Duas questões-chave nortearam a investigação:

a) Quais são as principais lacunas de qualidade encontradas entre as expectativas e a percepção do serviço recebido no comercio varejista, na ótica das consumidoras de vestuários?

b) Como diferentes categorias de clientes percebem a qualidade do serviço nos centros comerciais por eles frequentados?

Dados do IBGE (2013) mostram que o comércio de tecidos, artigos de vestuário e calçados destacou-se tanto em relação ao número de empresas quanto no que se refere ao pessoal ocupado e ao pagamento de salários, retiradas e outras remunerações. Contando com 22,5\% do número total de empresas (261.814), sua participação na receita líquida de revenda do varejo correspondeu a 10\% (R\$ 65,2 bilhões). A massa de salários, retiradas e outras remunerações pagas totalizou R $\$ 9,9$ bilhões, 0 que correspondeu a 16,8\% do total; ao passo que o número de pessoas ocupadas, 1,2 milhão, representou $18,9 \%$ do segmento varejista. A atividade atingiu a maior taxa de margem de comercialização do varejo (72,1\%), seguida do comércio de produtos alimentícios, bebidas e fumo, com 55,3\%, diante de uma taxa de $36 \%$ no total do segmento. Dados da Associação Brasileira do Vestuário (2010) indicavam que, em 2010, o Brasil era o quinto maior produtor mundial de peças de vestuário. A indústria produzia 6,5 bilhões de peças por ano, sendo 55,5\% voltadas para o público feminino. Segundo estudo da AT Kearney, o Brasil é o maior mercado de vestuário da América do Sul, com US\$ 42 bilhões em vendas, três vezes mais que o México, nono colocado no ranking, com US\$ 14 bilhões (VIANA, 2013).

\section{FUDAMENTAÇÃO TEÓRICA}

Lovelock e Wright (2006) afirmam que as expectativas podem variar entre diferentes grupos demográficos, como aqueles associados ao gênero, à idade e ao estrato social. A essência dos serviços seria representada por um ato ou desempenho oferecido de uma parte à outra; seriam atividades econômicas que criam valores e fornecem benefícios para clientes em tempos e lugares específicos. Gronroos (1984) aponta a qualidade percebida de um serviço como o resultado de um processo de avaliação em que o consumidor compara suas expectativas com o serviço que efeti- 
vamente percebeu receber, contrapondo o serviço percebido e o serviço esperado. O resultado desse processo seria a qualidade do serviço percebida. A qualidade de um serviço, como percebida por clientes, tem duas dimensões: uma dimensão técnica ou de resultado e uma dimensão funcional ou relacionada ao processo. O autor aponta a imagem corporativa como uma dimensão da qualidade que seria função do quê e como o serviço foi realizado.

Parasuraman, Zeithaml e Berry (1985) traduziram a qualidade de serviço na discrepância entre expectativas dos clientes em relação ao serviço e a percepção destes em relação ao desempenho do serviço prestado. Quão maior for o alinhamento dos serviços oferecidos por um núcleo ou centro comercial às necessidades dos clientes, maiores as chances que estes o escolham para realizar suas compras. A qualidade do serviço é avaliada pela comparação entre as expectativas dos clientes e a percepção destes sobre o serviço recebido. Na mesma direção que Gronroos (1984) propôs, com base no paradigma da desconfirmação, o modelo das lacunas de qualidade, constituído por um conjunto de cinco lacunas que representam as possíveis distorções entre compreensão de necessidades dos clientes, planejamento e realização do serviço e percepções distintas sobre o resultado final do serviço oferecido. O cliente tende a ficar satisfeito se a percepção do serviço recebido for maior que suas expectativas.

\subsection{FATORES DE ATRATIVIDADE EM DIFERENTES FORMATOS DO VAREJO}

A escolha de uma área comercial depende de fatores de atratividade associados às lojas (variedade dos produtos, estrutura física e atendimento dos funcionários) e de fatores exógenos (concentração e quantidade de lojas, facilidade de acesso, localização, atmosfera, segurança no entorno e estacionamento). As pesquisas e os estudos empíricos acerca do tema envolvem variáveis ligadas diretamente aos negócios individuais e aquelas associadas ao ambiente da área comercial. Dennis, Marsland e Cockett (2002) desenvolveram um estudo sobre atratividade com seis centros comerciais do Reino Unido, variando de pequenos centros em bairros a grandes centros fora da cidade. Os entrevistados declararam suas percepções de importância para 38 atributos. Os resultados indicaram uma forte correlação entre a atratividade e o volume de vendas. Mesmo com muitas outras considerações nas decisões de onde fazer compras, parece haver uma estreita associação entre a atratividade e o número de lojas, especialmente aquelas mais desejadas pelos consumidores. Isso seria compreensível, considerando que os centros mais atraentes atrairiam os varejistas mais bem-sucedidos. 
Para Reimers e Clulow (2004), um centro comercial varejista oferece conveniência, quando se minimizam os custos espaciais, temporais e de esforço de compras. Os resultados apontaram três insights importantes. Em primeiro lugar, por meio das medidas de concentração do varejo, o shopping foi o que ofereceu maior comodidade espacial aos consumidores. Em segundo lugar, o desaparecimento das áreas comerciais poderia estar ligado à sua incapacidade de satisfazer às necessidades de uma sociedade orientada para a conveniência. E, em terceiro lugar, em uma área comercial, a desvantagem competitiva em termos de conveniência espacial poderia ser compensada por outras funções não comerciais. Os resultados mostram que o shopping oferece ao cliente uma maior comodidade espacial, na forma de parada única para as compras; uma maior variedade de serviços comerciais e um horário de funcionamento prolongado. No comércio de bairro, as lojas individuais poderiam estar em localizações espacialmente não ideais, mas a proporção de funções de varejo e não varejo tende a ser mais atrativa. Ainda, Reimers e Clulow (2009) reafirmam que a conveniência de tempo tem uma influência marcante no comportamento de fidelidade dos consumidores e que as duas áreas - shopping e comércio de bairro - diferem em relação a esse atributo-chave. Por outro lado, Teller e Elms (2010), também analisando a atratividade de áreas comerciais como shopping e comércio de bairro, identificaram claramente que o mix de lojas, a gama de produtos e o ambiente são os principais influenciadores da atratividade, e que a oferta de uma aglomeração mais atraente para os consumidores pode compensar os déficits relacionados com a conveniência.

Maronick (2007) analisou os fatores de atratividade da área comercial e de entretenimento ligados à região central do porto de Baltimore, EUA. Comparando dados colhidos ao longo de 23 anos, o estudo mostra que residentes de Baltimore, como os da maioria das cidades, são mais propensos a escolher os shopping centers suburbanos do que as áreas comerciais centrais das cidades. No entanto, o autor avalia que, com o crescimento residencial observado em áreas adjacentes ao centro, é provável que no futuro a área abrigue varejistas nacionais frequentemente encontrados nos shopping centers suburbanos.

Borgers e Vosters (2011) desenvolveram um estudo com o objetivo de compreender as principais razões que levariam consumidores holandeses que frequentam o comércio nos centros das cidades a se deslocarem a grandes shopping centers construídos na periferia. Os resultados apontaram que a tarifa de estacionamento e a arquitetura (design) foram os atributos mais eficazes em termos de atratividade, seguidos por natureza das lojas âncoras e tipo de tráfego permitido no arruamento dos outlets. Com moderado efeito, apareceram tamanho e formato das ruas e acesso por 
carro. Cadeias de lojas, acesso por transporte coletivo e tipo de entretenimento foram os atributos apontados com menor atratividade.

O estudo de Luceri e Latusi (2012) avaliou o impacto de variáveis associadas ao perfil dos clientes sobre o número de lojas visitadas ao realizarem suas compras. Os resultados apontaram que mulheres, por perceberem maiores benefícios ou pouco esforço na mobilidade entre lojas, tendem a visitar mais lojas do que os homens. Os consumidores que apreciam a atividade de compras tendem a concentrar as compras em menos lojas do que aqueles que percebem as compras como um mero dever. Segundo os autores, conhecendo características dos consumidores que desencadeiam o uso e o aumento do número de lojas secundárias, os varejistas podem direcionar seus programas de comunicação e de fidelidade. Os varejistas poderiam melhorar a atmosfera da loja, propiciando uma experiência de compra mais agradável para os consumidores.

Castells e Guimarães (2007), em estudo realizado com varejo de bairros, observaram que em centros dessa natureza, ao contrário do comércio da região central, o cliente normalmente tem afinidade com o proprietário da loja. Na grande maioria, os proprietários moram no bairro onde mantêm o seu estabelecimento, possuindo relações de vizinhança e, em alguns casos, até de parentesco com os clientes, fornecedores e outros comerciantes. O estabelecimento comercial torna-se um espaço de sociabilidade, muitas vezes, tido como um “ponto de encontro” dos amigos. O comerciante desempenha um papel de destaque e de alguma maneira se cria uma rede social de comunicação com seus moradores.

O formato de shopping center se destaca pela crescente importância que vem assumindo na expansão do varejo no País. De acordo com a Associação Brasileira de Shopping Centers (2012), o setor conta com 438 shoppings que empregam mais de 775 mil pessoas. O mercado de shopping centers é responsável por 18,3\% do varejo nacional e por 2\% do PIB. Ainda em plena expansão no País, o setor fechou o ano 2011 com um faturamento de R\$ 108 bilhões. Os shoppings mantêm vários serviços em um mesmo local, como cinemas e restaurantes, bancos e outros serviços de conveniência, além de proporcionarem estacionamento, conforto e segurança. A rápida expansão urbana, os grandes congestionamentos de trânsito, a redução dos estacionamentos nas vias públicas, o aumento da criminalidade e o tempo escasso dos cidadãos têm contribuído para que, cada vez mais, os consumidores realizem suas compras em shopping centers.

Hastreiter, Marchetti e Prado (2000) procuraram estabelecer estatisticamente a relação entre a satisfação do consumidor e nove fatores de atratividade: acesso e estacionamento, arquitetura e atmosfera, qualidade e preço, mix de lojas, serviços, 
comodidade e conveniência, atendimento e compostos promocionais, praça de alimentação, lazer e entretenimento. El-Adly (2007) levantou os fatores de atratividade em shopping centers dos Emirados Árabes Unidos e segmentou os compradores de acordo com as suas dimensões. O estudo revelou seis dimensões que atraem os clientes: conforto, entretenimento, diversificação, essência, conveniência e luxo. O estudo de Hastreiter e Marchetti (2013) conclui que as pessoas vão ao shopping fazer as mesmas atividades, porém, com objetivos diferentes. Um mesmo comportamento de compra ou consumo no shopping estaria associado com benefícios distintos como, por exemplo, praticidade, convívio social, conciliação de interesses e convívio familiar. Estes, por sua vez, levariam ao alcance de estados finais desejados diferentes, como independência, reconhecimento/aceitação, demonstração de afeto, harmonia familiar e felicidade. O estudo aponta, ainda, que as escolhas dos consumidores estão relacionadas ao gênero, sexo e idade.

Campos e Lundberg (2013) avaliaram a importância de fatores de atratividade de shopping centers para um público jovem. Constataram que no terço dos atributos mais importantes, quatro deles estão associados diretamente à dimensão acessibilidade: acesso mediante transporte coletivo, proximidade à residência, localização do shopping e preço cobrado pelo estacionamento. A dimensão recreação e entretenimento aparece com três variáveis: cinema, agradabilidade e diversidade dos restaurantes da praça de alimentação. Na dimensão diversidade e qualidade da oferta, aparecem variedade de segmentos do comércio, espaço de serviços e qualidade das lojas âncoras. Completam a lista dos mais importantes, na dimensão ambiente, facilidade de locomoção interna e ambiente refrigerado.

Os atributos ou fatores de atratividade relacionados à decisão em frequentar uma área comercial estão associados a um grupo de dimensões do serviço prestado pelos lojistas e também à área comercial como um todo. A literatura oferece dezenas de atributos presentes em importantes estudos empíricos. Os trabalhos de Neuhaus e Bessegato (2005), Hepp (2006), Leidens (2006), Muraro (2007) e Aki (2009) avaliaram especificamente o serviço em lojas de vestuário, contemplando um grande número de atributos e fatores de atratividade. Os fatores com os quais se avalia um negócio específico do varejo, via de regra, estão presentes nos estudos de avaliação dos centros comerciais e/ou nos fatores motivacionais que levam clientes a frequentarem diferentes áreas comerciais. O Quadro 1 mostra as dimensões nas quais se enquadram os atributos utilizados em diferentes estudos empíricos, nacionais e internacionais, relacionados ao processo de escolha ou aos fatores motivacionais que levam clientes a frequentarem uma ou outra área comercial: 
Quadro 1 - Principais dimensões investigadas nos estudos empíricos

\begin{tabular}{|c|c|}
\hline Dimensão & Estudos \\
\hline Acesso e transporte & $\begin{array}{l}\text { Ibrahim e Wee (2002), Yavas (2003), El-Adly (2007), Reimers e Clulow } \\
\text { (2009), Tellers e Elms (2010), Borgers e Vosters (2011), Hastreiter e Mar- } \\
\text { chetti (2013), Campos e Lundberg (2013). }\end{array}$ \\
\hline Ambiente e atmosfera & $\begin{array}{l}\text { Ibrahim e Wee (2002), Yavas (2003), El-Adly (2007), Reimers e Clulow } \\
\text { (2009), Teller e Elms (2010), Borgers e Vosters (2011), Hastreiter e Mar- } \\
\text { chetti (2013), Hedhli, Chebat e Sirgy (2013), Campos e Lundberg (2013). }\end{array}$ \\
\hline Estrutura & $\begin{array}{l}\text { Ibrahim e Wee (2002), Yavas (2003), El-Adly (2007), Reimers e Clulow } \\
\text { (2009), Tellers e Elms (2010), Borgers e Vosters (2011), Hastreiter e Mar- } \\
\text { chetti (2013), Hedhli, Chebat e Sirgy (2013), Campos e Lundberg (2013). }\end{array}$ \\
\hline Diversidade e mix & $\begin{array}{l}\text { Ibrahim e Wee (2002), Yavas (2003), El-Adly (2007), Reimers e Clulow } \\
\text { (2009), Tellers e Elms (2010), Borgers e Vosters (2011), Hastreiter e Mar- } \\
\text { chetti (2013), Hedhli, Chebat e Sirgy (2013), Campos e Lundberg (2013), } \\
\text { Kesari e Atulkar (2016). }\end{array}$ \\
\hline Atendimento & Ibrahim e Wee (2002), Yavas (2003). \\
\hline Horários/conveniência & $\begin{array}{l}\text { Yavas (2003), El-Adly (2007), Reimers e Clulow (2009), Hastreiter e Mar- } \\
\text { chetti (2013), Hedhli, Chebat e Sirgy (2013), Campos e Lundberg (2013), } \\
\text { Kesari e Atulkar (2016). }\end{array}$ \\
\hline Serviços & $\begin{array}{l}\text { Yavas (2003), El-Adly (2007), Reimers e Clulow (2009), Tellers e Elms } \\
\text { (2010), Hastreiter e Marchetti (2013), Campos e Lundberg (2013). }\end{array}$ \\
\hline Entretenimento & $\begin{array}{l}\text { Yavas (2003), El-Adly (2007), Reimers e Clulow (2009), Tellers e Elms } \\
\text { (2010), Borgers e Vosters (2011), Hastreiter e Marchetti (2013), Hedhli, } \\
\text { Chebat e Sirgy (2013), Campos e Lundberg (2013), Kesari e Atulkar (2016). }\end{array}$ \\
\hline Alimentação & $\begin{array}{l}\text { Ibrahim e Wee (2002), Yavas (2003), El-Adly (2007), Reimers e Clulow } \\
\text { (2009), Tellers e Elms (2010), Borgers e Vosters (2011), Hastreiter e Mar- } \\
\text { chetti (2013), Campos e Lundberg (2013). }\end{array}$ \\
\hline Segurança & $\begin{array}{l}\text { Yavas (2003), El-Adly (2007), Reimers e Clulow (2009), Hastreiter e Mar- } \\
\text { chetti (2013), Hedhli, Chebat e Sirgy (2013), Campos e Lundberg (2013). }\end{array}$ \\
\hline Preço & $\begin{array}{l}\text { Ibrahim e Wee (2002), Yavas (2003), El-Adly (2007), Reimers e Clulow } \\
\text { (2009), Tellers e Elms (2010), Hastreiter e Marchetti (2013), Campos e Lun- } \\
\text { dberg (2013), Kesari e Atulkar (2016). }\end{array}$ \\
\hline
\end{tabular}

O estudo de Zhelnina (2011) aponta que o crescente número de shopping centers tem contribuído para sua maior diferenciação, uma tendência de segmentação e segregação das fronteiras sociais sutis que surgiram nos primeiros anos de seu surgimento. Agora, há centros comerciais de “elite” com lojas caras e centros de varejo especializados em vendas e bens com desconto. A demarcação social entre os compradores é feita com base na aparência, no gosto, na interpretação de marcas de vestuário e em outras características do consumidor.

A literatura tem abordado outros aspectos que envolvem antecedentes e influências sobre as motivações para a frequência e lealdade de clientes em áreas comerciais. Os espaços de concentração de comércio e serviços costumam ser áreas públicas que aglutinam um grande número de pessoas que ali convergem pelo interesse 
utilitário, economia, funcionalidade e conveniência para as compras e pelo interesse hedônico, entretenimento, atmosfera e convívio social (HEDHLI; CHEBAT; SIRGY, 2013; KESARI; ATULKAR, 2016; DAS; VARSHNEYA, 2017).

O estudo de Rahman, Wong e Yu (2016) sugere que compradores altamente orientados para a moda obtêm maior valor de compra não apenas diretamente da experiência de compra em si, mas também de suas percepções positivas da personalidade do shopping. Os valores de compra dos consumidores impactam sua intenção de frequentar os shopping centers, particularmente entre os jovens líderes de moda. Afirmam os autores que é razoável sugerir que empresários e gestores centrem sua atenção no posicionamento de moda dos seus shoppings, e que trabalhem para fornecer valores utilitários e hedônicos para atrair os segmentos de mercado que valorizam.

Outras questões como presença do verde nos espaços públicos internos dos centros comerciais (HAMI; MOULA; MAULAN, 2018), presença de elementos da arte na ambientação de lojas e espaços comuns (NALETELICH; PASWAN, 2018) e disponibilidade e uso de redes de wi-fi (REN et al., 2017) têm sido apontadas como atributos que influenciam a frequência de clientes, sua intenção de compra e sua possibilidade de retorno.

\section{METODOLOGIA}

O Diagrama 1 apresenta o esquema metodológico utilizado na investigação. Com base na literatura, foram coletados os atributos e fatores de atratividade mais importantes na oferta de serviços por centros comerciais tradicionais, de rua e shopping centers:

Diagrama 1 - Esquema metodológico

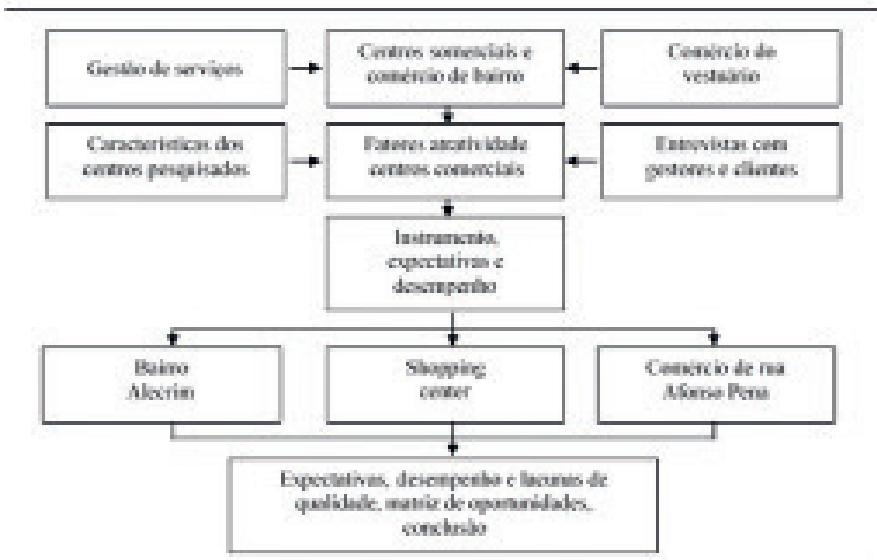

Fonte: os autores. 
Na primeira fase, foram coletadas dezenas de fatores associados à atratividade do comércio varejista em bairros e centros comerciais, levando-se em conta os seus formatos e o segmento do comércio de vestuário. Realizou-se um levantamento in loco das atividades de cada área, suas características e especificidades; e também um conjunto de entrevistas semiestruturadas com comerciantes e clientes com o objetivo de identificar elementos básicos e atributos que contribuíssem para a formulação do instrumento quantitativo de avaliação do serviço oferecido. A segunda fase consistiu na aplicação do questionário junto a uma amostra de clientes de cada centro. Foram identificados os principais atributos na percepção das clientes e as lacunas de qualidade e construídas as matrizes de oportunidades.

\subsection{CARACTERÍSTICAS E ESPECIFICIDADES DOS CENTROS COMERCIAIS}

O Bairro comercial Alecrim, criado oficialmente em 1911, tem resistido, notadamente, ao processo de expansão urbana, apontado nos últimos anos em Natal. Isso coloca-o como bairro de características originais, remontadas ao longo dos últimos 100 anos. Dispõe de uma área de 344,33 hectares e uma população residente de 30.428 habitantes. O comércio (54,62\%) e a prestação de serviços (47,27\%) representam suas principais atividades (PREFEITURA MUNICIPAL DO NATAL, 2012). De acordo com a Federação do Comércio do Rio Grande do Norte (Fecomércio-RN) (2012), o Bairro Alecrim é considerado o maior centro comercial do Estado e um dos 100 maiores do País, compreendendo mais de seis mil estabelecimentos em toda a sua extensão.

O centro comercial da Avenida Afonso Pena e suas adjacências corta os dois bairros de maior poder aquisitivo da Cidade: Tirol e Petrópolis. Neste estudo, o centro comercial foi delimitado ao Norte pela Avenida Joaquim Fagundes; ao Leste pela Avenida Hermes da Fonseca; ao Oeste pela Avenida Rodrigues Alves e ao Sul pela Rua Potengi. Essa região concentra um núcleo de clínicas e hospitais, prestadores de serviço, bares e restaurantes. Destaca-se, ainda, pelo comércio e pelo aglomerado de boutiques que comercializam roupas de marcas renomadas.

O terceiro centro comercial é um shopping center. Está situado em um dos mais importantes cruzamentos da Cidade de Natal, RN, na Avenida Salgado Filho (BR-101) com a Avenida Bernardo Vieira. O shopping dispõe de três pavimentos dis-

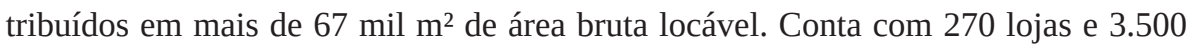
vagas de estacionamento cobertas. Emprega diretamente mais de 6.500 pessoas. A Tabela 1 apresenta as principais características dos três centros comerciais. 
Tabela 1 - Características dos centros comerciais

\begin{tabular}{|c|c|c|c|}
\hline Natureza & Shopping* & Alecrim** & Afonso Pena ${ }^{* * *}$ \\
\hline Lojas de vestuário & 109 & 185 & 66 \\
\hline Outras lojas de varejo & 148 & 789 & 163 \\
\hline $\begin{array}{l}\text { Restaurantes, bares e } \\
\text { cafés }\end{array}$ & 45 & 179 & 53 \\
\hline Lojas âncoras & 13 & - & - \\
\hline Cinema/teatro & 9 & - & - \\
\hline Supermercados & 1 & 1 & 2 \\
\hline Serviços/bancos & Diversos & Diversos & Diversos \\
\hline $\begin{array}{l}\text { Fonte: os autores. } \\
\text { Nota: * Dados disponív } \\
\text { ** Dados levantados rel } \\
* * * \text { Dados levantados re }\end{array}$ & $\begin{array}{l}\text { Iidway Mall S } \\
\text { o comercial ce } \\
\text { rno da Avenid }\end{array}$ & & \\
\hline
\end{tabular}

Para validar e/ou complementar os atributos apontados na literatura, foi realizada uma pesquisa qualitativa com a realização de entrevistas semiestruturadas com 10 clientes e 10 gestores de lojas de vestuário de cada área comercial, perfazendo um total de 60 entrevistas. As entrevistas ofereceram subsídios para a montagem do instrumento quantitativo da investigação, mormente quanto ao quadro dos atributos ou fatores de atratividade, e apontaram características e especificidades de cada área comercial.

De posse das informações encontradas nos estudos empíricos, das características e especificidades dos centros comerciais, e ainda somadas aos atributos apontados nas entrevistas semiestruturadas, foi possível consolidar o conjunto de atributos utilizado na pesquisa. Para tanto, foram usados critérios de similaridade, coerência, precisão e exatidão de linguagem e completude. Vários atributos foram revistos com o objetivo de eliminar aglutinações e justaposições. Os 23 atributos selecionados são apresentados no Quadro 2. Antes da confecção do instrumento quantitativo, o conjunto de atributos foi submetido a um grupo de 12 especialistas e 30 clientes do varejo de vestuário que opinaram tanto sobre a representatividade quanto em relação ao nível de compreensão e clareza da linguagem utilizada na sentença que define cada atributo. 
Quadro 2 - Lista de atributos utilizados na pesquisa

\begin{tabular}{|c|c|}
\hline N. & Relação de atributos \\
\hline 1 & $\begin{array}{l}\text { Atendimento dos vendedores (cordialidade; atenção; presteza) nas lojas que compõem a área } \\
\text { comercial. }\end{array}$ \\
\hline 2 & Aparência dos funcionários (limpa, arrumada e profissional). \\
\hline 3 & Conhecimento técnico dos vendedores referente aos produtos e procedimentos de venda. \\
\hline 4 & $\begin{array}{l}\text { Agradabilidade da área comercial (conforto sonoro, aroma ambiental, espaço para descanso com } \\
\text { assentos ou bancos, presença de praças e áreas verdes, limpeza das vias públicas, iluminação). }\end{array}$ \\
\hline 5 & Facilidade de circulação na área comercial (trânsito, vias amplas e livres de obstáculos, sinalização). \\
\hline 6 & Segurança na área comercial e no seu entorno. \\
\hline 7 & $\begin{array}{l}\text { Estacionamento na área comercial e no seu entorno (disponibilidade adequada de vagas para } \\
\text { estacionar). }\end{array}$ \\
\hline 8 & Proximidade entre a área comercial e a sua residência. \\
\hline 9 & Facilidade de acesso à área comercial por meio do transporte coletivo. \\
\hline 10 & Disponibilidade de restaurantes, lanchonetes, cafés e bares. \\
\hline 11 & $\begin{array}{l}\text { Disponibilidade de calçadas e rampas de acesso, orientação e comunicação facilitadora para } \\
\text { pessoas portadoras de deficiência ou mobilidade reduzida. }\end{array}$ \\
\hline 12 & $\begin{array}{l}\text { Disponibilidade de conveniência como bancos, casas lotéricas, supermercados, cinema, telefones } \\
\text { públicos. }\end{array}$ \\
\hline 13 & Aparência externa das lojas (conservação, arquitetura, exposição de produtos na vitrine). \\
\hline 14 & Existência de lojas renomadas e produtos diferenciados (marcas famosas e exclusivas). \\
\hline 15 & $\begin{array}{l}\text { Disponibilidade de grandes lojas de departamentos como Marisa, C \& A, Riachuelo, Renner, } \\
\text { Americanas. }\end{array}$ \\
\hline 16 & Horário de funcionamento das lojas na área comercial. \\
\hline 17 & $\begin{array}{l}\text { Agradabilidade do ambiente interno das lojas (ventilação, iluminação, espaço, exposição dos } \\
\text { produtos). }\end{array}$ \\
\hline 18 & Oferta de novidades (lançamento de produtos e tendências da moda). \\
\hline 19 & Variedade de lojas e sortimento de produtos oferecidos. \\
\hline 20 & Preço dos produtos oferecidos. \\
\hline 21 & Qualidade dos produtos disponíveis. \\
\hline 22 & Promoções e possibilidade de descontos nos preços dos produtos. \\
\hline 23 & Utilização da área comercial para passear, circular, encontrar amigos. \\
\hline
\end{tabular}

\subsection{INSTRUMENTO DE PESQUISA}

O instrumento de pesquisa foi construído em três módulos. No primeiro, buscou-se investigar o perfil sociodemográfico dos clientes, compreendendo: faixa etária, escolaridade, renda familiar, ocupação principal, meio de transporte utilizado para se locomover à área comercial e frequência de visita às três áreas comerciais. Na segunda seção, os clientes foram demandados a responder sobre o grau de importân- 
cia atribuído a cada um dos 23 atributos investigados, no que se refere à sua decisão em frequentar uma área comercial. A importância atribuída a um atributo do serviço representa, em sua essência, as expectativas do cliente. As respostas foram apontadas em uma escala Likert de 11 pontos, variando de 0 (não importante) a 10 (muito importante). No último módulo, os clientes foram arguidos em relação ao desempenho do serviço recebido pelos clientes específicos de cada uma das áreas comerciais nos 23 atributos arrolados. Suas respostas foram registradas sobre uma escala Likert de 11 pontos, com variação de 0 (péssimo) a 10 (excelente). Nele, foi incluída uma questão solicitando a avaliação da área comercial como um todo. Antes da aplicação definitiva do instrumento, realizou-se um pré-teste com 30 clientes, sendo 10 de cada centro comercial. Esse procedimento permitiu realizar os últimos ajustes no instrumento.

\subsection{POPULAÇÃO E AMOSTRA}

O universo da pesquisa é constituído por mulheres com idades entre 20 e 69 anos da Cidade de Natal, consumidoras de vestuários e frequentadoras de uma das áreas comerciais do estudo. O número e o perfil das frequentadoras para cada área comercial é desconhecido. As populações foram consideradas independentes e as amostras foram calculadas para uma população infinita. Cada amostra foi estratificada por faixa etária. O plano amostral é apresentado na Tabela 2. A coleta dos dados foi realizada in loco, por conveniência, em dependências de cada centro comercial, especialmente nas áreas de descanso e alimentação. Antes de aplicar o questionário, o entrevistador perguntava à consumidora se ela realizava compras de produtos do vestuário naquele centro comercial e, em caso afirmativo, iniciava o procedimento de coleta.

Tabela 2 - Plano amostral

\begin{tabular}{|c|c|c|c|}
\hline Centros comerciais & Universo & Faixa etária* & Tamanho** \\
\hline \multirow{6}{*}{$\begin{array}{l}\text { Erro } 5 \% \text {, alfa }=95 \% \text {, } \mathrm{p}=50 \% \\
\text { * Faixas etárias com base no perfil da } \\
\text { população economicamente ativa da Cida- } \\
\text { de de Natal. } \\
\text { ** Número de mulheres entrevistadas por } \\
\text { faixa etária, em cada área comercial. } \\
\text { *** Total de mulheres entrevistadas em } \\
\text { cada área comercial }\end{array}$} & \multirow{6}{*}{$\begin{array}{l}\text { Perfil e número de } \\
\text { frequentadoras de } \\
\text { cada área comercial: } \\
\text { desconhecidos }\end{array}$} & 20-29 anos & 114 \\
\hline & & 30-39 anos & 92 \\
\hline & & 40-49 anos & 83 \\
\hline & & 50-59 anos & 59 \\
\hline & & 60-69 anos & 37 \\
\hline & & Subtotal $* * *$ & 385 \\
\hline Sotfware StatDisk, versão 10.3.0 & Total geral & & 1.155 \\
\hline
\end{tabular}




\section{RESULTADOS}

A análise dos resultados ocorreu a partir de 1.155 questionários válidos, sendo 385 mulheres em cada área comercial, com estratificação por faixa etária, segundo o plano amostral. As Tabela 3 e 4 mostram o perfil das mulheres respondentes por bairro. Na área do Bairro Alecrim, há predominância de clientes com escolaridade até o segundo grau completo (92,7\%), renda até 5 salários mínimos (97\%) e que utilizam o ônibus (79\%) como meio de transporte para se deslocar até a área comercial. $\mathrm{Na}$ outra ponta, na área da Avenida Afonso Pena, predomina o nível de escolaridade superior ou pós-graduado (77,1\%), renda familiar superior a 6 salários mínimos (60\%) e modo de transporte no deslocamento por carro (67\%).

Tabela 3 - Perfil das respondentes

\begin{tabular}{|c|c|c|c|c|}
\hline & & Alecrim & Shopping & Afonso Pena \\
\hline \multirow{4}{*}{ 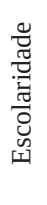 } & Fundamental & $31,1 \%$ & $6,5 \%$ & $1,6 \%$ \\
\hline & Secundário & $61,6 \%$ & $50,9 \%$ & $21,3 \%$ \\
\hline & Superior & $7 \%$ & $36,1 \%$ & $38,4 \%$ \\
\hline & Pós-graduação & $0,3 \%$ & $6,5 \%$ & $38,7 \%$ \\
\hline \multirow{4}{*}{ 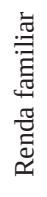 } & Menor que 2 salários & $48 \%$ & $23 \%$ & $3 \%$ \\
\hline & 2 a 5 salários & $49 \%$ & $62 \%$ & $37 \%$ \\
\hline & 6 a 10 salários & $3 \%$ & $13 \%$ & $45 \%$ \\
\hline & Mais que 10 salários & $0 \%$ & $2 \%$ & $15 \%$ \\
\hline \multirow{5}{*}{ 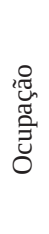 } & Sem ocupação ou outros & $22 \%$ & $38 \%$ & $27 \%$ \\
\hline & Autônomo & $16 \%$ & $7 \%$ & $8 \%$ \\
\hline & Empresário & $1 \%$ & $2 \%$ & $4 \%$ \\
\hline & Empregado & $51 \%$ & $48 \%$ & $51 \%$ \\
\hline & Aposentado & $10 \%$ & $5 \%$ & $10 \%$ \\
\hline
\end{tabular}

Fonte: os autores. 
Tabela 4 - Meios de transporte e frequência em cada área comercial

\begin{tabular}{|c|c|c|c|c|}
\hline & & Alecrim & Shopping & Afonso Pena \\
\hline \multirow{4}{*}{ 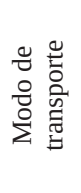 } & Carro & $14 \%$ & $30 \%$ & $67 \%$ \\
\hline & Ônibus & $79 \%$ & $63 \%$ & $28 \%$ \\
\hline & Táxi & $0 \%$ & $0 \%$ & $1 \%$ \\
\hline & Outros & $7 \%$ & $7 \%$ & $4 \%$ \\
\hline \multirow{5}{*}{ 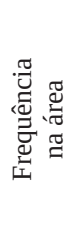 } & Diária & $37 \%$ & $25 \%$ & $26 \%$ \\
\hline & Semanal & $6 \%$ & $24 \%$ & $30 \%$ \\
\hline & Quinzenal & $18 \%$ & $15 \%$ & $15 \%$ \\
\hline & $\begin{array}{l}\text { Mensal ou } \\
\text { bimensal }\end{array}$ & $29 \%$ & $27 \%$ & $18 \%$ \\
\hline & Raramente & $10 \%$ & $9 \%$ & $11 \%$ \\
\hline
\end{tabular}

Fonte: os autores.

O perfil no shopping aponta uma situação intermediária entre esses dois bairros. A ocupação e a frequência de visitas das áreas têm perfis menos diferenciados entre os diferentes clientes dos bairros. Perguntadas sobre a frequência às outras áreas comerciais, as clientes do Bairro Alecrim disseram frequentar raramente ou nunca frequentar as áreas do shopping (49\%) e menos ainda a Avenida Afonso Pena (88\%). Muitos clientes do shopping relataram frequentar pelos menos uma vez por mês o Bairro Alecrim (43\%) e também a Avenida Afonso Pena (84\%). Já 18\% das clientes da Avenida Afonso Pena disseram frequentar pelo menos uma vez por mês o shopping e apenas 10\% disseram frequentar o Bairro Alecrim uma vez por mês.

\subsection{IMPORTÂNCIA DOS ATRIBUTOS E LACUNAS DA QUALIDADE DO SERVIÇO}

As clientes assinalaram, mediante a aplicação do módulo 2 do questionário, o grau de importância que conferem a cada atributo. O grau de importância mede as expectativas que os clientes têm em relação aos atributos. Para cada atributo, foram calculadas as médias das notas conferidas pelas clientes de cada área comercial. A média geral também foi obtida para todas as 1.155 respondentes. Nas três áreas, segurança foi o atributo mais importante para as clientes. No Bairro Alecrim e no shopping o atributo menos importante foi a existência de lojas e marcas renomadas. Na Avenida Afonso Pena, as clientes consideram menos importante o atributo disponibilidade de grandes lojas de departamento. A Tabela 5 mostra as médias das expectativas, desempenhos e lacunas de qualidade por atributo em cada área comercial e os rankings respectivos das expectativas e das lacunas de qualidade percebidos pelas clientes: 
Tabela 5 - Expectativas, desempenho e lacunas de qualidade dos atributos em cada área comercial

\begin{tabular}{|c|c|c|c|c|c|c|c|c|c|c|c|c|c|c|c|c|}
\hline \multirow{2}{*}{ Atributo } & \multirow{2}{*}{ RG } & \multicolumn{5}{|c|}{ Alecrim } & \multicolumn{5}{|c|}{ Shopping } & \multicolumn{5}{|c|}{ Afonso Pena } \\
\hline & & $\mathbf{R}$ & ME & MD & Lac & RLac & $\mathbf{R}$ & ME & MD & Lac & RLac & $\mathbf{R}$ & ME & MD & Lac & RLac \\
\hline Segurança na área & 1 & 1 & 9,06 & 1,54 & $-7,52$ & 1 & 1 & 9,46 & 8,35 & $-1,11$ & 7 & 1 & 9,63 & 4,65 & $-4,98$ & 2 \\
\hline Acesso pessoas mobilidade reduz. & 2 & 9 & 8,3 & 1,82 & $-6,48$ & 2 & 2 & 9,36 & 7,28 & $-2,08$ & 2 & 2 & 9,46 & 3,29 & $-6,17$ & 1 \\
\hline Ambiente interno das lojas & 3 & 3 & 8,54 & 5,55 & $-2,99$ & 7 & 3 & 9,23 & 8,99 & $-0,24$ & 14 & 4 & 9,03 & 8,63 & $-0,40$ & 18 \\
\hline Conhecimento dos vendedores & 4 & 5 & 8,41 & 5,99 & $-2,42$ & 9 & 5 & 9,15 & 7,75 & $-1,40$ & 5 & 6 & 8,98 & 8,32 & $-0,66$ & 13 \\
\hline Promoções e descontos & 5 & 2 & 8,9 & 6,69 & $-2,21$ & 13 & 4 & 9,18 & 6,77 & $-2,41$ & 1 & 13 & 8,42 & 6,91 & $-1,51$ & 7 \\
\hline Qualidade dos produtos & 6 & 4 & 8,5 & 6,25 & $-2,25$ & 12 & 6 & 8,94 & 8,37 & $-0,57$ & 10 & 5 & 9,03 & 8,9 & $-0,13$ & 20 \\
\hline Atendimento dos vendedores & 7 & 10 & 8,23 & 5,87 & $-2,36$ & 11 & 7 & 8,94 & 7,43 & $-1,51$ & 4 & 7 & 8,97 & 8,54 & $-0,43$ & 17 \\
\hline Variedade e sortimento das lojas & 8 & 6 & 8,4 & 7,30 & $-1,10$ & 18 & 8 & 8,88 & 8,66 & $-0,22$ & 15 & 9 & 8,74 & 8,66 & $-0,08$ & 21 \\
\hline Oferta de novidades & 9 & 15 & 7,72 & 6,53 & $-1,19$ & 17 & 12 & 8,63 & 8,22 & $-0,41$ & 13 & 3 & 9,05 & 8,48 & $-0,57$ & 15 \\
\hline Preço dos produtos & 10 & 7 & 8,35 & 6,94 & $-1,41$ & 15 & 14 & 8,55 & 6,88 & $-1,67$ & 3 & 12 & 8,46 & 6,83 & $-1,63$ & 6 \\
\hline Agradabilidade da área & 11 & 11 & 8,12 & 3,12 & $-5,00$ & 4 & 9 & 8,84 & 8,74 & $-0,10$ & 16 & 15 & 8,3 & 7,54 & $-0,76$ & 12 \\
\hline Horário funcionamento lojas & 12 & 8 & 8,35 & 7,87 & $-0,48$ & 21 & 13 & 8,62 & 8,58 & $-0,04$ & 17 & 17 & 8,09 & 7,49 & $-0,60$ & 14 \\
\hline Aparência externa das lojas & 13 & 16 & 7,71 & 5,33 & $-2,38$ & 10 & 11 & 8,64 & 8,94 & 0,30 & 19 & 11 & 8,64 & 8,51 & $-0,13$ & 19 \\
\hline Aparência dos funcionários & 14 & 14 & 7,9 & 5,80 & $-2,10$ & 14 & 17 & 8,29 & 8,31 & 0,02 & 18 & 10 & 8,73 & 8,89 & 0,16 & 22 \\
\hline Disponibiliza outros serviços & 15 & 12 & 8,11 & 7,31 & $-0,80$ & 20 & 10 & 8,66 & 8,13 & $-0,53$ & 12 & 19 & 8,01 & 6,97 & $-1,04$ & 9 \\
\hline Estacionamento na área & 16 & 21 & 7,19 & 2,57 & $-4,62$ & 5 & 16 & 8,52 & 7,28 & $-1,24$ & 6 & 8 & 8,86 & 5,02 & $-3,84$ & 3 \\
\hline Facilidade de circulação & 17 & 18 & 7,53 & 3,80 & $-3,73$ & 6 & 15 & 8,52 & 7,97 & $-0,55$ & 11 & 14 & 8,42 & 6,62 & $-1,80$ & 5 \\
\hline Restaurantes, cafés e bares & 18 & 19 & 7,51 & 7,38 & $-0,13$ & 22 & 18 & 8,22 & 8,84 & 0,62 & 21 & 18 & 8,04 & 7,53 & $-0,51$ & 16 \\
\hline Acesso transporte coletivo & 19 & 13 & 8,06 & 6,96 & $-1,10$ & 19 & 19 & 8,16 & 7,36 & $-0,80$ & 9 & 22 & 6,75 & 5,56 & $-1,19$ & 8 \\
\hline Proximidade com residência & 20 & 17 & 7,54 & 6,19 & $-1,35$ & 16 & 22 & 7,11 & 6,2 & $-0,91$ & 8 & 21 & 7,78 & 6,77 & $-1,01$ & 10 \\
\hline Passear e encontrar amigos & 21 & 22 & 5,42 & 2,90 & $-2,52$ & 8 & 20 & 8,06 & 8,43 & 0,37 & 20 & 20 & 8,01 & 7,13 & $-0,88$ & 11 \\
\hline Disponib. grandes lojas depto. & 22 & 20 & 7,41 & 2,34 & $-5,07$ & 3 & 21 & 7,7 & 8,57 & 0,87 & 22 & 23 & 6,37 & 2,71 & $-3,66$ & 4 \\
\hline Lojas e marcas renomadas & 23 & 23 & 4,83 & 4,92 & 0,09 & 23 & 23 & 6,48 & 8,59 & 2,11 & 23 & 16 & 8,24 & 8,64 & 0,40 & 23 \\
\hline
\end{tabular}

Fonte: os autores.

Nota: $\mathrm{R}$ = Ranking das médias das expectativas em cada área. RG = Ranking da média geral das expectativas. RLac = Ranking das lacunas de qualidade.

$\mathrm{ME}=$ Média das expectativas das clientes em cada atributo. $\mathrm{MD}=$ Média do desempenho atribuído pelas clientes a cada atributo. Lac = Lacunas de qualidade em cada atributo. 
O teste de correlação de Spearman foi aplicado com o objetivo de identificar o alinhamento entre os rankings de importância dos atributos percebidos pelas clientes nos diferentes centros comerciais. Destaca-se uma baixa compatibilidade entre as prioridades das clientes do Bairro Alecrim e da Avenida Afonso Pena (0,543); esse resultado é reforçado quando se constata que as clientes do Bairro Alecrim nunca ou raramente fazem suas compras na Avenida Afonso Pena (88\%). Há mais pontos de congruência entre as clientes do Bairro Alecrim e do shopping (0,854). Entre as clientes da Avenida Afonso Pena e do shopping, o alinhamento de prioridades em relação ao grau de importância conferido aos atributos ficou em uma faixa intermediária, alcançando o valor de 0,752. A Tabela 6 apresenta os resultados do teste:

Tabela 6 - Teste de Spearman para os rankings

\begin{tabular}{lrrr}
\hline & Alecrim & Afonso Pena & Shopping \\
\hline Alecrim & 1,00 & 0,543 & 0,854 \\
Afonso Pena & 1,00 & 0,752 \\
Shopping & & 1,00 \\
\hline Fonte: OS autores. \\
Nota: Correlação é significante ao nível de 0,01.
\end{tabular}

O modelo das lacunas de qualidade compara as expectativas com o desempenho. Assim, pode-se verificar em que medida e em quais atributos cada área comercial atende às necessidades dos clientes. As lacunas de qualidade (Lac) são calculadas pela diferença entre desempenho (MD) e expectativas (ME) em cada atributo.

No Bairro Alecrim, em todos os atributos, com exceção da existência de lojas e marcas renomadas, houve lacunas negativas (déficit) de qualidade, ou seja, o desempenho da área comercial para as clientes de vestuário ficou além de suas expectativas. Os maiores déficits de qualidade ocorreram na segurança $(-7,52)$, acesso para pessoas com deficiência ou mobilidade reduzida $(-6,48)$, disponibilidade de grandes lojas de departamento $(-5,07)$, agradabilidade $(-5,00)$ e estacionamento $(-4,62)$.

No shopping houve lacunas de qualidade negativas em 17 atributos, sendo os maiores em promoções e descontos $(-2,41)$, acesso para pessoas com deficiência ou mobilidade reduzida $(-2,08)$, preço dos produtos $(-1,67)$, atendimento $(-1,51)$ e conhecimento dos vendedores $(-1,40)$. Em seis atributos, o desempenho da área superou as expectativas das clientes, ocorrendo a maior lacuna positiva de qualidade para a existência de lojas e marcas renomadas $(2,11)$.

Na Avenida Afonso Pena o desempenho superou as expectativas das clientes apenas em dois atributos: aparência dos funcionários $(0,02)$ e existência de lojas 
e marcas renomadas $(2,11)$. Os maiores déficits de qualidade ocorreram nos atributos: acesso para pessoas com deficiência ou mobilidade reduzida $(-6,17)$, segurança $(-4,98)$, estacionamento $(-3,84)$, disponibilidade de grandes lojas de departamento $(-3,66)$ e facilidade de circulação $(-1,80)$.

O quadro geral das lacunas de qualidade suscita uma discussão mais profunda sobre as prioridades que os gestores deveriam ter no sentido de apoiar ou tomar decisões no gerenciamento dos serviços oferecidos. As ações dos gestores devem voltar-se prioritariamente para os maiores déficits de qualidade associados à condição que os clientes projetam nas suas expectativas. Assim, o gestor deve ter um olhar atento sobre a dimensão da lacuna e o grau de importância que os clientes conferem a cada atributo. Atributos com maior déficit e com mais alto grau de importância devem merecer maior destaque na atenção dos gestores. Na Tabela 7 são apresentados os 10 atributos mais importantes, consoante projeção das clientes de cada área comercial.

É notável que no rol dos atributos mais importantes nas três áreas comerciais as projeções das clientes nas amostras independentes coincidem em sete deles (grifados na cor cinza). Embora, em todos, as lacunas sejam negativas, os casos mais preocupantes são aqueles de importância alta com grande dimensão de lacuna correspondente. Esse é o caso da segurança e do acesso para pessoas com deficiência ou mobilidade reduzida nas três áreas. No Bairro Alecrim, além destes, estão entre as maiores lacunas ambiente interno das lojas e conhecimento dos vendedores. No shopping aparecem ainda promoções e descontos, atendimento e conhecimento dos vendedores e qualidade dos produtos. Na Avenida Afonso Pena, adicionalmente, aparece estacionamento entre as maiores lacunas. 
Tabela 7 - Atributos mais importantes para as clientes e lacunas de qualidade em cada área

\begin{tabular}{|c|c|c|c|c|c|c|c|c|c|}
\hline & \multicolumn{3}{|l|}{ Alecrim } & \multicolumn{3}{|c|}{ Shopping } & \multicolumn{3}{|c|}{ Afonso Pena } \\
\hline $\mathrm{R}$ & Atributo & $\mathrm{L}$ & RL & Atributo & $\mathrm{L}$ & RL & Atributo & $\mathrm{L}$ & $\mathrm{RL}$ \\
\hline 1 & Segurança na área & $-7,52$ & 1 & Segurança na área & $-1,11$ & 7 & Segurança na área & $-4,98$ & 2 \\
\hline 2 & $\begin{array}{l}\text { Promoções e des- } \\
\text { contos }\end{array}$ & $-2,21$ & 13 & $\begin{array}{l}\text { Acesso pessoas com } \\
\text { deficiência }\end{array}$ & $-2,08$ & 2 & $\begin{array}{l}\text { Acesso pessoas com } \\
\text { deficiência }\end{array}$ & $-6,17$ & 1 \\
\hline 3 & $\begin{array}{l}\text { Ambiente interno } \\
\text { das lojas }\end{array}$ & $-2,99$ & 7 & $\begin{array}{l}\text { Ambiente interno das } \\
\text { lojas }\end{array}$ & $-0,24$ & 14 & Oferta de novidades & $-0,57$ & 15 \\
\hline 4 & $\begin{array}{l}\text { Qualidade dos pro- } \\
\text { dutos }\end{array}$ & $-2,25$ & 12 & $\begin{array}{l}\text { Promoções e des- } \\
\text { contos }\end{array}$ & $-2,41$ & 1 & $\begin{array}{l}\text { Ambiente interno das } \\
\text { lojas }\end{array}$ & $-0,40$ & 18 \\
\hline 5 & $\begin{array}{l}\text { Conhecimento dos } \\
\text { vendedores }\end{array}$ & $-2,42$ & 9 & $\begin{array}{l}\text { Conhecimento dos } \\
\text { vendedores }\end{array}$ & $-1,40$ & 5 & $\begin{array}{l}\text { Qualidade dos pro- } \\
\text { dutos }\end{array}$ & $-0,13$ & 20 \\
\hline 6 & $\begin{array}{l}\text { Variedade e sorti- } \\
\text { mento lojas }\end{array}$ & $-1,10$ & 18 & $\begin{array}{l}\text { Qualidade dos pro- } \\
\text { dutos }\end{array}$ & $-0,57$ & 10 & $\begin{array}{l}\text { Conhecimento dos } \\
\text { vendedores }\end{array}$ & $-0,66$ & 13 \\
\hline 7 & Preço dos produtos & $-1,41$ & 15 & $\begin{array}{l}\text { Atendimento dos } \\
\text { vendedores }\end{array}$ & $-1,51$ & 4 & $\begin{array}{l}\text { Atendimento dos } \\
\text { vendedores }\end{array}$ & $-0,43$ & 17 \\
\hline 8 & $\begin{array}{l}\text { Horário lojas } \\
\text { funcionamento }\end{array}$ & $-0,48$ & 21 & $\begin{array}{l}\text { Variedade e sortimen- } \\
\text { to lojas }\end{array}$ & $-0,22$ & 15 & $\begin{array}{l}\text { Estacionamento na } \\
\text { área }\end{array}$ & $-3,84$ & 3 \\
\hline 9 & $\begin{array}{l}\text { Acesso pessoas com } \\
\text { deficiência }\end{array}$ & $-6,48$ & 2 & $\begin{array}{l}\text { Agradabilidade } \\
\text { da área }\end{array}$ & $-0,10$ & 16 & $\begin{array}{l}\text { Variedade e sortimen- } \\
\text { to lojas }\end{array}$ & $-0,08$ & 21 \\
\hline 10 & $\begin{array}{l}\text { Atendimento dos } \\
\text { vendedores }\end{array}$ & $-2,36$ & 11 & $\begin{array}{l}\text { Disponibiliza outros } \\
\text { serviços }\end{array}$ & $-0,53$ & 12 & $\begin{array}{l}\text { Aparência dos funcio- } \\
\text { nários }\end{array}$ & 0,16 & 22 \\
\hline
\end{tabular}

Fonte: os autores.

Nota: $\mathrm{R}$ = Ranking de importância do atributo na área comercial específica. $\mathrm{L}=$ Lacuna de qualidade. $\mathrm{RL}=$ Ranking da lacuna de qualidade na área comercial respectiva.

No Bairro Alecrim, entre as 10 maiores lacunas de qualidade, quatro correspondem a atributos mais importantes para as clientes: segurança, acesso para pessoas com deficiência ou mobilidade reduzida, ambiente interno das lojas e conhecimento dos vendedores. No shopping, recaíram entre os mais importantes: promoções e descontos, acesso para pessoas com deficiência ou mobilidade reduzida, atendimento e conhecimento dos vendedores, segurança e qualidade dos produtos. Na Avenida Afonso Pena, acesso para pessoas com deficiência ou mobilidade reduzida, segurança e estacionamento. Esses são os atributos que devem merecer maior atenção dos gestores.

Na outra ponta estão os atributos que são os menos importantes para as clientes e têm os menores déficits, ou o desempenho supera as expectativas dos clientes. O atributo existência de lojas e marcas renomadas aparece em último lugar no ranking de importância para as clientes do Bairro Alecrim e do shopping, e em $16^{\circ}$ para as clientes da Avenida Afonso Pena. Nas três áreas o desempenho superou as expectativas. É importante observar que o superávit ocorreu mesmo não existindo lojas e 
marcas renomadas na área comercial do Bairro Alecrim. É que naquela área as expectativas das clientes são notoriamente baixas em relação à presença delas.

Os resultados em conjunto indicam que as clientes do Bairro Alecrim, no geral, são menos exigentes que as clientes do shopping. É possível que esse nível de exigência esteja associado aos níveis de escolaridade e de renda das clientes. O Bairro Alecrim é reconhecido pela população da Cidade como um centro comercial popular (XAVIER, 2014). Os perfis das clientes da Avenida Afonso Pena e do shopping apontam níveis de renda e de escolaridade superiores ao perfil das clientes do centro comercial do Bairro Alecrim. Não obstante, o comércio de vestuário do Bairro Alecrim apresenta as maiores lacunas de qualidade entre os três centros comerciais avaliados. Na maioria dos atributos, o comércio do Bairro Alecrim tem déficit de qualidade maior ou superávit menor que do shopping e da Avenida Afonso Pena. Os Gráficos 1 e 2 mostram os perfis analisados. Os atributos estão numerados e têm a mesma ordenação apresentada na Tabela 5.

Gráfico 1 - Perfil dos níveis de expectativas em cada atributo por centro comercial

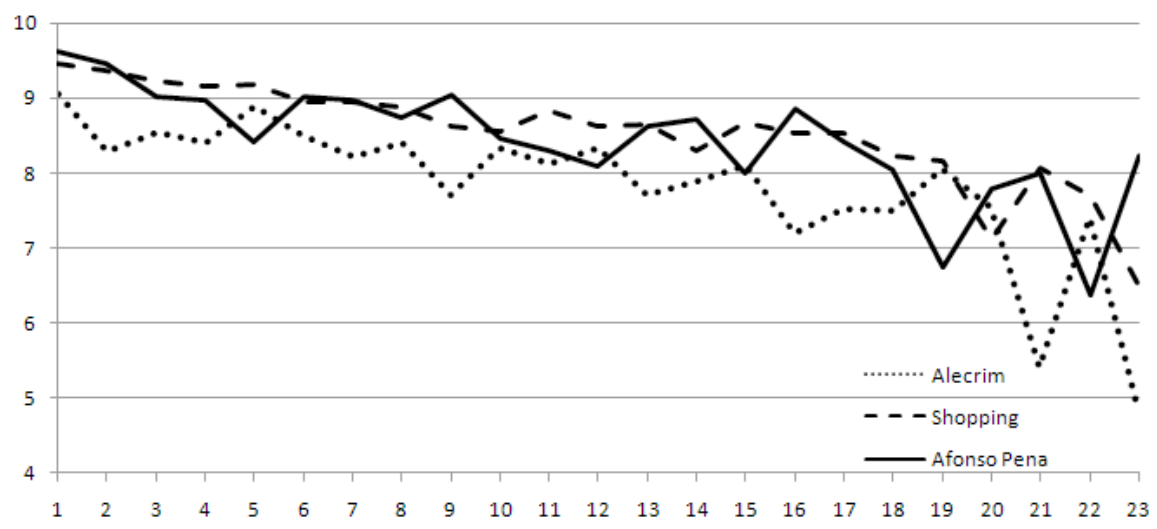

Fonte: os autores.

Gráfico 2 - Perfil das lacunas de qualidade dos atributos por centro comercial

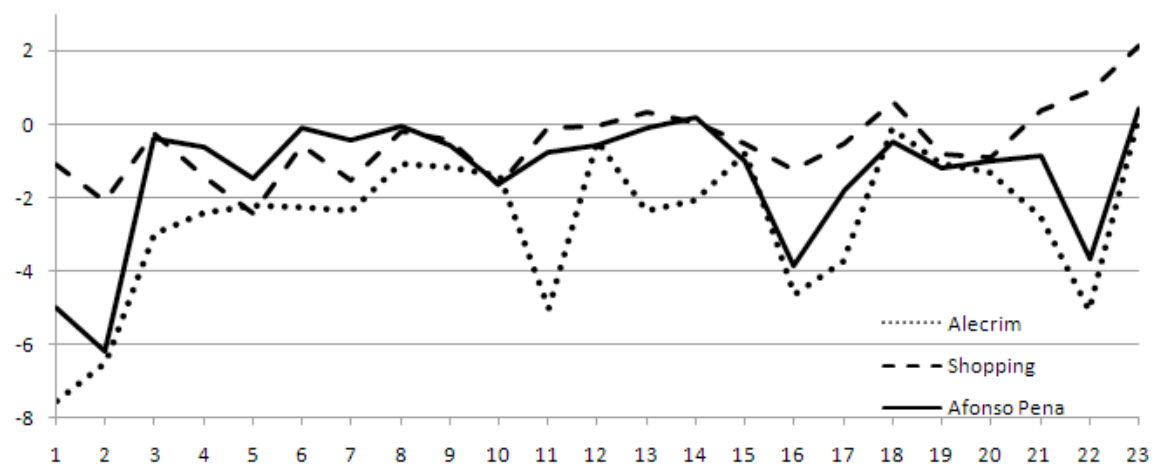

Fonte: os autores. 
Em certa medida, esses resultados se aproximam daqueles encontrados por Parente et al. (2012), ao compararem a satisfação de clientes com o comércio varejista popular e com o varejo em shopping centers. Os clientes indicaram uma maior satisfação geral com os shoppings e expressaram uma percepção negativa do comércio popular varejista de rua. As únicas vantagens desse local em relação aos shoppings foram associadas a um melhor acesso e a uma melhor relação custo-benefício. Entre as desvantagens, o destaque foi a infraestrutura. Para os autores, nesse processo, a vantagem da facilidade de acesso dos distritos de rua está em declínio, enquanto a insatisfação com a falta de infraestrutura está subindo. A construção de shopping centers em regiões de baixa renda estaria acelerando o processo de deterioração do comércio varejista de rua mais popular.

\section{CONCLUSÃO}

Neste artigo avaliaram-se as expectativas de clientes e o serviço prestado por três importantes centros comerciais da Cidade de Natal. Os centros foram representados por um comércio de bairro popular, por um comércio de rua (strip retail), diferenciado, e pelo maior shopping center da Cidade. Com base em três amostras independentes, os resultados mostraram que há um conjunto de atributos que são comuns às clientes do setor de vestuário. Três dimensões aparecem destacadamente: segurança, atendimento e produto. É notável que, apesar das diferenças significativas no formato da área comercial e no perfil sociodemográfico de suas frequentadoras, 7 atributos comuns emergiram entre os 10 mais importantes de cada área. De um lado, aparecem os atributos segurança na área e acesso para pessoas com deficiência ou mobilidade reduzida. De outro, aparecem atributos com vínculos mais estreitos com o varejo: ambiente interno das lojas, atendimento e conhecimento dos vendedores, qualidade e variedade e sortimento dos produtos.

Mesmo com os elementos comuns apontados, os grupos distintos de frequentadoras apontam diferenças significativas no ordenamento das respostas no que se refere ao grau de importância conferido aos atributos. O teste de Spearman apontou um alto desalinhamento entre as prioridades das clientes do Bairro Alecrim (comércio popular) e as das clientes da Avenida Afonso Pena (comércio de alto poder aquisitivo). $\mathrm{O}$ atributo acesso para pessoas com deficiência ou mobilidade reduzida foi o segundo mais importante na Avenida Afonso Pena e o nono no Bairro Alecrim; promoções e descontos foi o segundo atributo mais importante no Bairro Alecrim e, apenas, o $13^{\circ}$ na Avenida Afonso Pena. 
No quesito qualidade dos serviços oferecidos, chama a atenção a quantidade de lacunas negativas de qualidade apontadas pelas clientes. Constatou-se déficit de qualidade nos 10 atributos mais importantes em todas as áreas comerciais. Com o confronto entre os graus de importância e as lacunas de qualidade de cada atributo, é possível recomendar ações imediatas aos gestores, no sentido de aperfeiçoar a oferta dos serviços em cada área. Aqueles atributos que recaem no rol dos mais importantes com maiores lacunas negativas de qualidade devem receber a atenção prioritária dos gestores no processo de melhoria do serviço.

Os resultados mostram menores lacunas de qualidade verificadas no ambiente do shopping center, especialmente aquelas vinculadas às características não utilitárias como um espaço seguro para passear e encontrar amigos e a disponiblidade de bares e restaurantes, indicando uma maior satisfação dos clientes do shopping center em relação às outras duas áreas comerciais. Os achados de Hedhli, Chebat e Sirgy (2013), Kesari e Atulkar (2016) e Das e Varshneya (2017) não apenas confirmam o aumento da satisfação dos clientes mediante a oferta de estímulos hedônicos, bem como apontam que construtos de prazer e emoção influenciam positivamente a intenção de revisitar o centro comercial e da propaganda boca a boca.

Por outro lado, o shopping center obteve níveis de qualidade superiores em relação às outras áreas comerciais, em todos os atributos vinculados à infraestrutura como estacionamento, acesso por transporte coletivo, acesso para pessoas com mobilidade reduzida e segurança. O estudo de Parente et al. (2012), ratificando esse comportamento, recomenda que os donos de lojas presentes nos distritos comerciais de rua ou de bairro devem criar associações de pares para coordenar esforços, juntamente com autoridades do governo, no sentido de melhorar o equipamento urbano (calçadas, iluminação, estacionamento), bem como a segurança nesses locais de varejo.

Por fim, os resultados sugerem que o comércio no bairro popular tende a atrair clientes menos exigentes. Não obstante o grau de exigência observado, esses clientes perceberam níveis mais baixos na qualidade do serviço recebido. Embora a pesquisa tenha abarcado um número significativo de atributos da qualidade e da atratividade do varejo, limitou-se a apreender e a analisar a percepção de clientes mulheres para o comércio de vestuário. Novas investigações podem ser levadas a cabo considerando outros segmentos do comércio e outras estratificações nas categorias de clientes. 


\section{REFERÊNCIAS}

AKI, A. Y. Acesso ao mercado para lojas de roupas. 2009. Disponível em: <http:// www.biblioteca.sebrae.com.br>. Acesso em: 19 ago. 2012.

ASSOCIAÇÃO BRASILEIRA DE SHOPPING CENTERS. Disponível em: <http:// www.portaldoshopping.com.br>. Acesso em: 18 ago. 2012.

ASSOCIAÇÃO BRASILEIRA DO VESTUÁRIO. 2010. Disponível em: <http:// www.abravest.org.br>. Acesso em: 03 dez. 2013.

BORGERS, A.; VOSTERS, C. Assessing preferences for mega shopping centres: a conjoint measurement approach. Journal of Retailing and Consumer Services, v. 18, p. 322-332, 2011.

CAMPOS, D. F.; LUNDBERG, F. A. C. Satisfação e atratividade: como o público jovem avalia os shopping centers. Revista Eletrônica em Administração da Universidade Potiguar, v. 5, n. 2, p. 79-98, 2013.

CASTELLS, A. N. G.; GUIMARÃES, A. C. R. Pinceladas sobre as práticas comerciais em um bairro popular de Florianópolis. Cuadernos de Antropología Social, n. 26, p. 69-86, 2007.

DAS, G.; VARSHNEYA, G. Consumer emotions: Determinants and outcomes in a shopping mall. Journal of Retailing and Consumer Services, v. 38, p. 177-185, 2017.

DENNIS, C.; MARSLAND, D.; COCKETT, T. Central place practice: shopping centre attractiveness measures, hinterland boundaries and the UK retail hierarchy. Journal of Retailing and Consumer Services, v. 9, p. 185-199, 2002.

EL-ADLY, M. I. Shopping malls attractiveness: a segmentation approach. International Journal of Retail e Distribution Management, v. 35, i. 11, p. 936-950, 2007.

FEDERAÇÃO DO COMÉRCIO RIO GRANDE DO NORTE. Disponível em: $<$ http:fecomerciorn.com.br>. Acesso em: 10 jul. 2012.

GRONROOS, C. A service quality model and its marketing implications. European Journal of Marketing, v. 18, i. 4, p. 36-44, 1984. 
HAMI, A.; MOULA, F. F.; MAULAN, S. B. Public preferences toward shopping mall interior landscape design in Kuala Lumpur, Malaysia. Urban Forestry and Urban Greening, v. 30, p. 1-7, 2018.

HASTREITER, S. T.; MARCHETTI, R. Z. Afinal, porque vamos ao shopping? Um estudo fundamentado na hierarquia de metas do consumidor. In: EnANPAD, 37., 2013, Rio de Janeiro. Anais... Rio de Janeiro, 2013.

HASTREITER, S. T.; MARCHETTI, R. Z.; PRADO, P. H. M. Tipologia de consumidores baseada nas razões e motivações de freqüência em shopping centers e a satisfação do consumidor. In: ANGELO, C. F.; SILVA, J. A. G. Varejo competitivo. São Paulo: Atlas, 2000.

HEDHLI, K.; CHEBAT, J. C.; SIRGY, M. J. Shopping well-being at the mall: Construct, antecedents, and consequences. Journal of Business Research, v. 66, p. 856863, 2013.

HEPP, C. P. T. Envolvimento e satisfação do consumidor: um estudo no varejo de vestuário em Curitiba. 2006. Dissertação (Mestrado em Administração)-Universidade Federal do Paraná, Curitiba, 2006.

IBGE. 2013. Disponível em: <http://www.ibge.gov.br>. Acesso em: 18 fev. 2014.

IBRAHIM, M. F.; WEE, N. C. The Importance of Entertainment in the Shopping Center Experience: Evidence from Singapore. Journal of Real Estate Portfolio Management, v. 8, i. 3, p. 239-254, 2002.

KESARI, B.; ATULKAR, S. Satisfaction of mall shoppers: A study on perceived utilitarian and hedonic shopping values. Journal of Retailing and Consumer Services, v. 31, p. 22-31, 2016.

LEIDENS, A. Investimentos no relacionamento e lealdade: um estudo no varejo de vestuário em Curitiba. 2006. Dissertação (Mestrado em Administração)-Universidade Federal do Paraná, Curitiba, 2006.

LINOVSKI, O. Beyond aesthetics: assessing the value of strip mall retail in Toronto. Journal of Urban Design, v. 17, n. 1, p. 81-99, 2012.

LOVELOCK, C.; WRIGHT, L. Serviços, Marketing e Gestão. 6. ed. São Paulo: Saraiva, 2006. 
LUCERI, B.; LATUSI, S. The importance of consumer characteristics and market structure variables in driving multiple store patronage. Journal of Retailing and Consumer Services, v. 19, p. 519-525, 2012.

MARONICK, T. J. Specialty retail center's impact on downtown shopping, dining, and entertainment. International Journal of Retail e Distribution Management, v. 35, n. 7, p. 556-568, 2007.

MIDWAY MALL SHOPPING. Disponível em: < http://midwaymall.com.br>. Acesso em: 01 set. 2012.

MURARO, M. L. C. A decisão de compra de vestuário no varejo de baixa renda: a influência das características do produto e da apresentação na loja. 2007. Dissertação (Mestrado em Administração)-Fundação Getúlio Vargas, São Paulo, 2007.

NALETELICH, K.; PASWAN, A. K. Art infusion in retailing: The effect of art genres. Journal of Business Research, v. 85, p. 514-522, 2018.

NEUHAUS, M. C.; BESSEGATO, A. M. O comportamento de compra do consumidor de vestuário no município de Giruá. In: SEMINÁRIOS EM ADMINISTRAÇÃO FEA-USP, 8., 2005, São Paulo. Anais... São Paulo, 2005. Disponível em: <http:// www.ead.fea.usp.br/semead/ 8semead/resultado/trabalhosPDF/344.pdf>. Acesso em: 20 jul. 2012.

PARASURAMAN, A.; ZEITHAML, V. A.; BERRY, L. A Conceptual model of service quality and its implications for future research. Journal of Marketing, v. 49, n. 2, p. 41-50, 1885.

PARENTE, J. et al. Main street retail districts or shopping centers? Comparing the preferences of low-income consumers. Brazilian Business Review, n. 1, p. 154179, 2012.

PARENTE, J.; MIOTTO, A. P.; BARKI, E. Marketing: Polos comerciais de rua. GVexecutivo, v. 6, n. 6, p. 49-54, 2007.

PREFEITURA MUNICIPAL DO NATAL. Secretaria Municipal de Meio Ambiente e Urbanismo. Disponível em: < http://www.natal.rn.gov.br/semurb/paginas/ctd102.html>. Acesso em: 10 ago. 2012. 
RAHMAN, O.; WONG, K. K.; YU, H. The effects of mall personality and fashion orientation on shopping value and mall patronage intension. Journal of Retailing and Consumer Services, v. 28, p. 155-164, 2016.

REIMERS, V.; CLULOW, V. Retail centres: it's time to make them convenient. International Journal of Retail e Distribution Management, v. 37, n. 7, p. 541-562, 2009.

REIMERS, V.; CLULOW, V. Retail concentration: a comparison of spatial convenience in shopping strips and shopping centres. Journal of Retailing and Consumer Services, v. 11, p. 207-221, 2004.

REN, Y. et al. Analyzing web behavior in indoor retail spaces. Journal of the Association for Information Science and Technology, v. 68, n. 1, p. 62-76, 2017.

TELLER, C.; ELMS; J. Managing the attractiveness of evolved and created retail agglomerations formats. Marketing Intelligence e Planning, v. 28, i. 1, p. 25-45, 2010.

VIANA, G. Brasil é o quinto país mais atrativo para varejo de roupas. Economia IG, 17 jun. 2013. Disponível em: <http://economia.ig.com.br/empresas/comercioservicos/2013-06-17/brasil-e-o-quinto-pais-mais-atrativo-para-varejo-de-roupas.html>. Acesso em: 03 dez. 2013.

XAVIER, D. C. S. Acessibilidade em área comercial: um estudo no bairro do Alecrim, Natal/RN. Dissertação (Mestrado em Arquitetura e Urbanismo)-Universidade Federal do Rio Grande do Norte, Natal, 2014.

YAVAS, U. A multi-attributes approach to understanding shopper segments. International Journal of Retail e Distribution Management, v. 31, i. 11, p. 541-48, 2003.

ZHELNINA, A. It's like a museum here: The shopping mall as public space. Laboratorium, v. 3, i. 2, p. 132-136, 2011. 


\section{Como citar este artigo:}

\section{ABNT}

CAMPOS, Domingos Fernandes et al. Qualidade do serviço no comércio varejista de vestuário: lacunas percebidas pela clientela feminina. RACE, Revista de Administração, Contabilidade e Economia, Joaçaba: Ed. Unoesc, v. 17, n. 2, p. 507-534, maio/ago. 2018. Disponível em: <http://editora.unoesc.edu.br/index.php/race>. Acesso em: dia/mês/ano.

\section{APA}

Campos, D. F., Garcia, E. F. L., Campos, D. C. F., \& Pereira Filho, E. (2018). Qualidade do serviço no comércio varejista de vestuário: lacunas percebidas pela clientela feminina. RACE, Revista de Administração, Contabilidade e Economia, 17(2), 507534. Recuperado em dia/mês/ano, de http://editora.unoesc.edu.br/index.php/race 